\title{
Review
}

Abhishek Mehta*, Anurag Negi, Aditi Verma and Kittu Jain

\section{Pooled prevalence estimates of malocclusion among Indian children and adolescents: a systematic review and meta-analysis}

https://doi.org/10.1515/ijamh-2020-0142

Received June 12, 2020; accepted July 9, 2020;

published online August 24, 2020

\section{Abstract}

Objectives: To estimate the pooled prevalence estimates of the malocclusion among child and adolescent population of India.

Contents: A comprehensive electronic search was carried to find studies related to assessing malocclusion in Indian children and adolescent population. Indices and classifications considered for pooled analysis were Dental Aesthetic Index, Index of Orthodontic Treatment Needs, Angles classification and terminal plane relationship of primary secondary molars. An eligibility criterion was prepared and quality assessment was done for all the eligible studies. Initial search produced 1090 titles. After removal of duplicates, 850 records were left for further screening. Eighty one articles were found eligible for full text reading. Finally 60 studies were included in this metaanalysis. Pooled prevalence was used to estimate overall effect, with 95\% confidence intervals (CI). Statistical difference between the two genders was calculated using chi square test.

Summary and outlook: The high prevalence of malocclusion is a public health problem around the world. The current status of burden of malocclusion among Indian children and adolescents is not known. Results of this

*Corresponding author: Dr. Abhishek Mehta, Department of Public Health Dentistry, Faculty of Dentistry, Jamia Millia Islamia, New Delhi, India, Phone: 91 9971209069, E-mail: amehta@jmi.ac.in. https://orcid.org/0000-0002-9192-7615

Anurag Negi, Department of Orthodontics, Faculty of Dentistry, Jamia Millia Islamia, New Delhi, India, E-mail: anegi@jmi.ac.in Aditi Verma, Department of Public Health Dentistry, Faculty of Dentistry, Jamia Millia Islamia, New Delhi, India,

E-mail: averma1@jmi.ac.in

Kittu Jain, Department of Public Health Dentistry, Rungta College of Dental Sciences \& Research, Bhilai, Chhattisgarh, India,

E-mail: dr.kittujain@gmail.com pooled analysis showed that prevalence of malocclusion among Indian children and adolescents has increased since the last national oral health survey. Prevalence of malocclusion ranged from $28.4 \%$ (CI 25.02, 31.9) to $66.7 \%$ (CI 50.7, 81.06) depending on the type of index or classification used for recording. Boys recorded higher cumulative prevalence than girls. These findings can be utilized by oral health policy makers to draft measures required for reducing this burden of malocclusion.

Keywords: adolescents; child; India; malocclusion; metaanalysis; pooled prevalence; systematic review.

\section{Introduction}

Malocclusion is defined as an irregularity of the teeth or a malrelationship between the dental arches beyond the range of what is accepted as normal. It is a multifactorial oral condition caused by general factors such as heredity, congenital defects, nutritional deficiencies and abnormal pressure habits. Malocclusion can also occur due to factors located in the dental arch such as anomalies of tooth size, shape, supernumerary teeth, dental caries and premature loss of primary teeth $[1,2]$. Measurement of extent and severity of malocclusion in an individual or population is done by indices such as Dental Aesthetic Index (DAI) [3], Index of Orthodontic Treatment Needs (IOTN) [4] or through Angles classification [5]. In primary dentition, terminal plane relationship of second molars is recorded to predict possible malocclusion in future [6]. Epidemiology of malocclusion is predominantly assessed based upon individual studies or national health oral survey although systematic reviews were being conducted in recent past among Iranian [7] and Chinese children [8]. There are no data available regarding the prevalence of malocclusion in global oral data bank of World Health Organization (WHO) because it considers malocclusion as a condition rather than a disease [9].

In India, only one national oral health survey has been conducted in the year 2002-03. This survey had reported a 
huge burden of untreated oral diseases including malocclusion across the country [10]. India is a young country with children of up to $0-14$ years of age constituting $29 \%$ of its population [11]. This can be considered as an opportunity for public health dentists and other oral health policy makers to plan and implement various primary preventive dentistry programs which can have long term benefits for our future generations. However, for planning such programme we need recent data on burden of oral diseases in India.

Currently, India has no mechanism for continuous surveillance of oral diseases nor there is no separate budget for oral health [12]. Therefore, to fill up the time gap before another nationwide survey is instituted, integrated studies such as a systematic review and meta-analysis can act as an invaluable tool to update oral health policy makers regarding the current burden of oral diseases in Indian population. Hence, we conducted this systematic review and meta-analysis with the aim to provide a comprehensive data to relevant stakeholders on prevalence of malocclusion among children and adolescent population of India. The patient, intervention, comparison, outcomes (PICO) method as applicable in relation to the topic of the review:

Patient: Indian children and adolescents less than or equal to 19 years of age

Intervention $=$ clinical examination for assessing malocclusion

Comparison: Not applicable

Outcomes: prevalence of malocclusion

Focused question:

What is the pooled prevalence of malocclusion among children and adolescent population in India?

\section{Methods}

The review protocol is registered with PROPSERO (registration number - CRD42018094345). PRISMA guidelines for conducting a systematic review were followed throughout the study period [13].

\section{Information sources and literature search}

Relevant articles were retrieved electronically by searching PubMed/MEDLINE, PubMed Central, Scopus, Complimentary index, Ebscohost, SciELO, Open DOAR, TRIP databases, Science Citation Index, Web of Science and finally Google Scholar. The search period was restricted from 1st January 2000 in order to obtain data from recent studies only. Other filters used were restrictions on language i.e. English and study participant's age should be under 20 years.

The search strategy was built with medical subject headings (MeSH) terms and relevant text words. The MeSH terms employed were "Malocclusion" [All Fields] AND "child" [All Fields] AND Adolescent [All fields] AND "India" [All Fields] as search strategy if the search engine permits. In addition, key words such as prevalence, Dental Aesthetic Index (DAI), Index of Orthodontic Treatment Needs (IOTN), Angle classification of malocclusion and primary dentition were used in order to broaden the search.

Relevant studies were searched independently by two authors (AM and AV). Initially titles were searched followed by abstracts and finally full texts were read. The first round of search was upto 30th April 2018; a second round was performed to include the entire list of relevant articles published upto 31st December 2019.

The calibration of the reviewers was done by conducting discussion sessions prior to the commencement of the study. A list of inclusion and exclusion criteria was prepared and both the reviewers were subjected to analyse 10 abstracts. Afterwards, an assessment was done and this procedure was repeated until a high inter-examiner agreement $(\mathrm{k}=0.92)$ was achieved. The results were then compared after the complete selection of the eligible articles by both the reviewers and in case of disagreement, a third reviewer (AN) was asked to review the article independently for inclusion. After the identification of articles in the databases, the articles were imported into Mendeley reference manager for the removal of duplicate articles. In addition, reference list of retrieved studies were searched to look out for more studies. In case of any clarification or additional data were required the concerned study author/s were contacted via e-mail.

\section{Study selection (inclusion and exclusion criteria)}

This systematic review concentrated on short listing the population or school based cross sectional studies conducted on Indian children and adolescents ( $<20$ years) assessing prevalence of malocclusion according to different indices and classifications. Studies that did not report the prevalence of dental malocclusion, sample size, abstracts submitted to conferences, case report studies, seminars, case-control studies and clinical trials not providing an accurate estimation of the prevalence were excluded from this review. Studies that did not obtain a minimum score of quality assessment and studies with a participant population of over 19 years of age were also excluded. 
Studies recording malocclusion as a part of a study on the associations with specific parameters such as nutrition status, socioeconomic status, quality of life, caries and periodontal diseases, studies conducted on special children, those suffering from any systemic condition or syndrome were not included in this review.

\section{Data extraction}

Relevant data were extracted by two independent reviewers (AM and $\mathrm{AV}$ ) from eligible studies under the following domains: study characteristics (study ID, first author's name, year of publication, sampling technique, total sample size, sample size in terms of gender and age, age range of the studied population); Description and assessment of exposure (overall and gender wise prevalence and severity of malocclusion according to different indices or classification).

Data for each index or classification were entered in terms of percentage of subjects falling into following categories:

(1) DAI- no malocclusion (<25), definite malocclusion (2630), severe malocclusion (31-35) and handicapping malocclusion (>35).

(2) IOTN-no , moderate and definitive need according severity of malocclusion

(3) Angle's classification-class - I, II, III and normal occlusion

(4) Primary dentition- mesial step, distal step and flush terminal.

\section{Quality assessment}

For assessing quality of the eligible studies for metaanalysis a checklist used in previous studies was utilized $[7,14]$. This checklist contains twelve (12) questions which are designed to assess the methodological quality of the observational studies. The main domains covered using these questions were: appropriateness and/or description of the (1) sample size, sample characteristics and sampling method (2) research question and study design (3) role of researcher (4) data collection methods (5) data analysis methods. For each question a score of 0 or 1 is assigned based on whether the answer is negative or positive, respectively. Two reviewers (AM and AV) carried out the quality assessment independently. Points of diversion were discussed with third reviewer (AN) and consensus was obtained for final score of the study in question.

\section{Statistical analysis}

Statistical analyses were performed in MedCalc software. Heterogeneity between the eligible studies was calculated using Cochrane $\mathrm{Q}$ and $\mathrm{I}^{2}$ Based on level of heterogeneity, random or fixed effects model were utilized to estimate the overall prevalence of malocclusion. Confidence interval was kept at 95\% and relevant forest plots were prepared for each scoring criteria category of indices and classification used in the review as well as for the overall prevalence. Gender wise pooled estimate of prevalence was calculated from the data available from the included studies. Statistical difference between the two gender was calculated using chi-square test at significance level of $\mathrm{p}<0.05$.

\section{Results}

\section{Literature search and quality assessment}

Figure 1 describes the whole sequence of literature search and shortlisting of studies. Initial search with pre- selected key words and identified MeSH terms from various databases produced 1,090 titles. After removal of duplicates, 850 records were left. All these remaining records were screened for their titles and abstracts; and 81 articles were found eligible for full text reading. Further, 21 studies were excluded for not meeting the inclusion criteria. Finally, sixty (60) articles were found eligible for final qualitative and quantitative analysis.

\section{Characteristics of included studies and pooled prevalence}

Basic characteristics of individual studies conducted using different malocclusion indices and classification are summarized in Tables 1, 2. Statistically significant heterogeneity was observed among primary studies therefore we used random effects model for estimation of pooled prevalence. Pooled estimates of malocclusion according to different measurement tools are described as follows:

\section{Dental Aesthetic Index (DAI)}

We found 34 studies [15-48] and one nationwide survey [10] eligible for pooling data where DAI was used for assessing malocclusion. The pooled prevalence was $28.4 \%$ (CI 25.02, 31.9) from a sample of 71409 children. Statistically significant higher proportion of malocclusion was seen among boys $(43.6 \%$, CI $35.5,51.9)$ as compared with 
girls [28.1\%, CI 23.1, 33.3, p<0.001]. "Very severe" type of malocclusion was observed in $4.8 \%$ (CI 3.7, 6.1) children (Table 3).

\section{Index of orthodontic treatment needs}

The total sample size obtained from 10 primary studies was more than nine thousand [49-58]. Overall pooled prevalence for any type of treatment need arising from malocclusion was $60.4 \%$ (CI 49.2, 71.1). More than one-third children were in need of definitive treatment. Five studies reported gender wise data [49-52, 58]. Higher overall prevalence was observed in boys in comparison to girls. However, more proportion of girls requires definite treatment (Table 3).

\section{Angles classification}

Eight studies had assessed malocclusion using Angles classification [59-66]. According to this classification, around two-third $(66.7 \%$, CI 50.7, 81.06) of 10,663 children were suffering from malocclusion. Here also boys reported higher overall prevalence than girls. Class I malocclusion was most common affecting more than half of the children (51.3\%. CI 36.2, 66.3). Class II malocclusion affected 10.2\% (CI 6.3, 14.9) and just $2.2 \%(0.8,4.2)$ children had class III malocclusion. Boys had higher proportion of class I and III whereas class II malocclusion was more prevalent in girls (Table 3).

\section{Terminal plane relationship of second primary molars}

Flush terminal plane and mesial step relationship together accounted for more than $80 \%$ cases. Less than ten percent children had distal step relationship and asymmetric molar relationship. Out of the seven studies [67-73] included in this category, only one study had provided gender wise data. The authors of this study reported that males had significant to highly significant higher prevalence for all the three molar relationships compared to females [70].

\section{Discussion}

The results of our review showed that the pooled overall prevalence of malocclusion in Indian children and adolescents ranged from $28.4 \%$ in studies conducted using DAI to more than $60 \%$ for IOTN and Angles classification. The National Oral Health Survey of India conducted in the year 2002-03 had reported the prevalence of malocclusion (using DAI) to be 23.6, and $23.9 \%$ in 12 and 15 years age group, respectively [10]. As compared to this nationwide survey our review reports a five percent increase in prevalence of malocclusion in Indian children. We included the data from this national survey except for five year old children since DAI is not recommended for this age group [75]. We did not find any other nationwide survey or

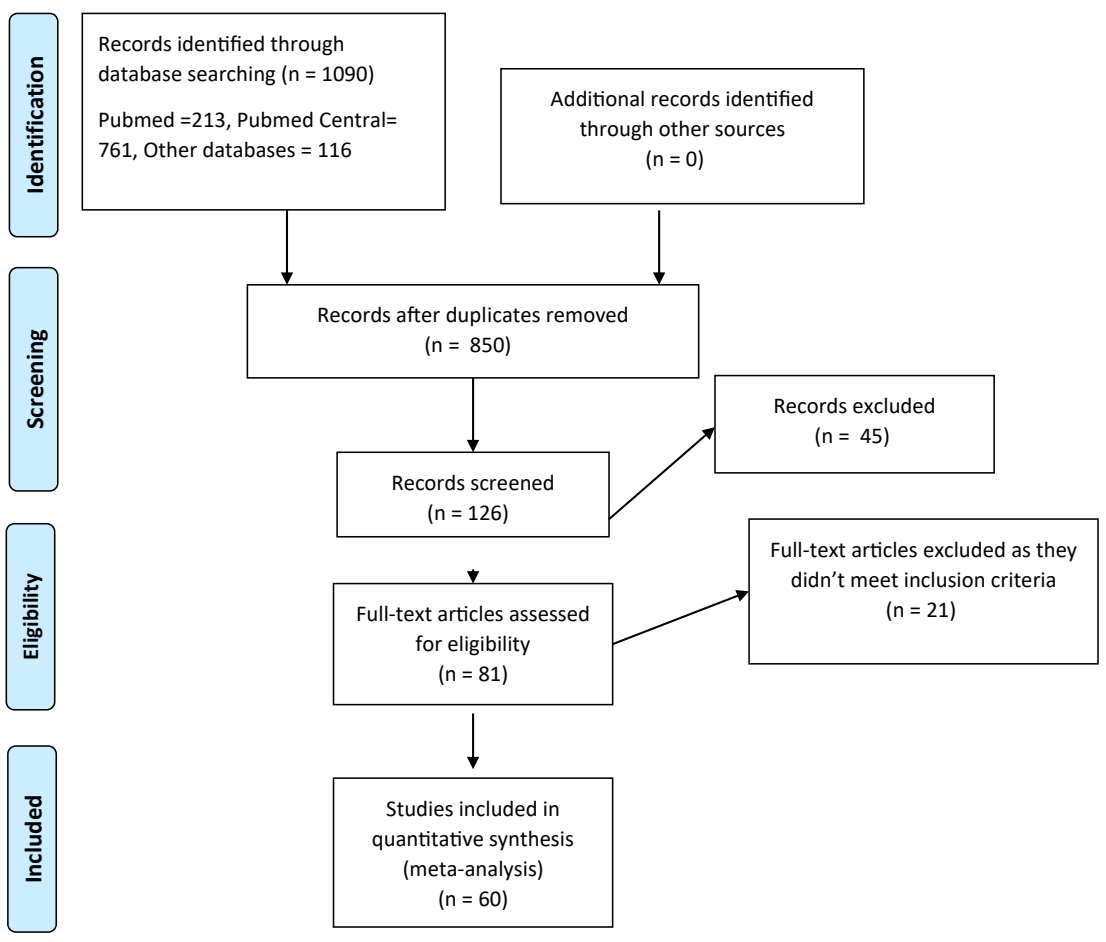

Figure 1: Literature search strategy. 
Table 1: characteristics of studies conducted to assess malocclusion using DAI.

\begin{tabular}{|c|c|c|c|c|c|c|c|c|c|}
\hline \multirow[t]{2}{*}{ S. no. } & \multirow[t]{2}{*}{ Author } & \multirow[t]{2}{*}{ QA score } & \multirow[t]{2}{*}{ Year of publication } & \multirow[t]{2}{*}{ Region of study } & \multirow[t]{2}{*}{ Sample size } & \multirow[t]{2}{*}{ Age group } & \multicolumn{3}{|c|}{$\begin{array}{l}\text { Prevalence o } \\
\text { malocclusior }\end{array}$} \\
\hline & & & & & & & Overall & Boys & Girls \\
\hline 1 & Baskaradoss JK [15] & 12 & 2013 & Tamilnadu & 1,800 & $11-15$ & 15.4 & 17 & 13.2 \\
\hline 2 & Bhardwaj VK [16] & 10 & 2011 & Himachal & 622 & $16-17$ & 20.4 & 20 & 21.1 \\
\hline 3 & Chandrashekher BR [17] & 11 & 2013 & Andhra & 1,268 & 15 & 18.2 & 13.5 & 23.9 \\
\hline 4 & Damle D [18] & 10 & 2014 & Haryana & 1,322 & $12-15$ & 23.6 & 24.9 & 22.2 \\
\hline 5 & Jha K [19] & 9 & 2011 & Uttar Pradesh & 697 & $12-15$ & 30.4 & 35.3 & 21.1 \\
\hline 6 & Nagalakshmi S [20] & 12 & 2017 & Tamilnadu & 1,078 & $12-15$ & 17.3 & 18.8 & 15.9 \\
\hline 7 & Shetty R [21] & 12 & 2018 & Karnataka & 1,001 & 15 & 30 & 29.3 & 30.8 \\
\hline 8 & Sanadhya S [22] & 9 & 2014 & Gujarat & 947 & $12-15$ & 33.4 & 38.1 & 27.6 \\
\hline 9 & Sivakumar KM [23] & 12 & 2009 & Karnataka & 1,000 & $12-15$ & 19.9 & 20.3 & 19.5 \\
\hline 10 & Sripriya N [24] & 12 & 2010 & Karnataka & 1,618 & $14-15$ & 21 & 22.3 & 19.5 \\
\hline 11 & Fotedar S [25] & 12 & 2013 & Himachal & 943 & $12-15$ & 40.8 & 57.2 & 53.3 \\
\hline 12 & Tak M [26] & 12 & 2013 & Rajasthan & 887 & $12-15$ & 33.3 & 38.7 & 26.3 \\
\hline 13 & Babu S [27] & 8 & 2005 & Karnataka & 300 & $13-15$ & 38.7 & 37.6 & 40 \\
\hline 14 & Chandra shekhar BR [28] & 9 & 2014 & Andhra & 1,484 & 15 & 17.9 & 13 & 23.6 \\
\hline 15 & Reddy VC [29] & 9 & 2011 & Tamilnadu & 300 & $12-15$ & 73.7 & - & - \\
\hline 16 & Deepthi A [30] & 11 & 2016 & Andhra & 200 & 12 & 31.5 & - & - \\
\hline \multirow[t]{2}{*}{17} & Hemapriya S [31] & 12 & 2013 & Tamilnadu & 500 & 12 & 75 & - & - \\
\hline & & & & & 500 & 15 & 75.4 & - & - \\
\hline 18 & Kaipa S [32] & 11 & 2009 & Andhra & 2,126 & $13-15$ & 49.2 & 53.6 & 44.7 \\
\hline 19 & Khan MK [33] & 11 & 2014 & Uttar Pradesh & 807 & $12-15$ & 30.7 & - & - \\
\hline 20 & Pruthi N [34] & 12 & 2013 & Himachal & 961 & $12-15$ & 52.8 & 54.1 & 50.3 \\
\hline 21 & Reddy S [35] & 10 & 2010 & Tamilnadu & 613 & 12 & 42.9 & 44.6 & 40.9 \\
\hline 22 & Gupta R [36] & 11 & 2015 & MP & 549 & $13-15$ & 21.5 & 24.2 & 19 \\
\hline 23 & Sushanth VH [37] & 10 & 2008 & Tamilnadu & 1,800 & $12-13$ & 21.1 & - & - \\
\hline 24 & Thakur AS [38] & 12 & 2017 & Karnataka & 525 & 12 & 13.8 & - & - \\
\hline 25 & Suma S [39] & 11 & 2011 & Andhra & 1,794 & 15 & 17.2 & 13.2 & 21.8 \\
\hline 26 & Shivakumar [40] & 11 & 2010 & Karnataka & 1,800 & $12-15$ & 20.1 & 19.9 & 20.4 \\
\hline 27 & Handa S [41] & 12 & 2013 & Haryana & 324 & $12-15$ & 38.91 & - & - \\
\hline 28 & John J [42] & 9 & 2011 & Tamilnadu & 613 & 12 & 43.7 & 70.2 & 73.4 \\
\hline 29 & Sivakumar V [43] & 12 & 2016 & Karnataka & 319 & 12 & 32.9 & - & - \\
\hline 30 & Prasad SN [44] & 8 & 2014 & Karnataka & 450 & $10-12$ & 65.2 & 69.4 & 61 \\
\hline 31 & Mallick S [45] & 12 & 2017 & Karnataka & 710 & 15 & 29.3 & 31.3 & 28 \\
\hline 32 & Kumar N [46] & 12 & 2010 & Karnataka & 2,001 & $12-15$ & 16.6 & - & - \\
\hline 33 & Singh A [47] & 12 & 2011 & Karnataka & 927 & 12 & 18 & - & - \\
\hline \multirow[t]{2}{*}{34} & Bali RK [10] & 11 & 2002 & India & 19,144 & 12 & 23.6 & - & - \\
\hline & & & & & 18,915 & 15 & 23.9 & - & - \\
\hline 35 & Gaikwad SS [48] & 9 & 2013 & Maharashtra & 880 & $12-15$ & 26.8 & - & - \\
\hline
\end{tabular}

systematic review conducted on Indian children for comparison with our data. Systematic reviews conducted in Iran [7] and China [8] have reported prevalence of 83.1 and $45.5 \%$ for any type of malocclusion in their native children. These reviews included studies conducted using Angles classification only.

It has been well-established that different types of malocclusions are associated with impaired oral health and function [76]. Possible consequences of untreated malocclusion are pain in temperomandibular joint/s region, increased risk of trauma, speech problem and difficulty in mastication leading to food restriction [77, 78]. In the current review, the overall pooled prevalence as per Angles classification was $66.7 \%$. Angles class 1 was the most prevalent type of malocclusion observed in Indian children. This finding is in consensus with studies and systematic reviews conducted in other countries $[7,8]$. Angles class I malocclusion can cause visible irregularities such as crowded anterior teeth or large midline diastema between incisors in the dental arches $[7,79]$. A systematic review conducted to assess global prevalence of class 3 malocclusion has reported a 
Table 2: Characteristics of studies conducted to assess malocclusion using IOTN, Angles Classification and terminal plane relationship.

\begin{tabular}{|c|c|c|c|c|c|c|c|c|c|}
\hline \multirow{2}{*}{$\begin{array}{l}\text { S. } \\
\text { no. }\end{array}$} & \multirow[t]{2}{*}{ First author } & \multirow{2}{*}{$\begin{array}{l}\text { Index/classification } \\
\text { used }\end{array}$} & \multirow{2}{*}{$\begin{array}{r}\text { QA } \\
\text { score }\end{array}$} & \multirow{2}{*}{$\begin{array}{r}\text { Publication } \\
\text { year }\end{array}$} & \multirow[t]{2}{*}{ Place of survey } & \multirow{2}{*}{$\begin{array}{r}\text { Sample } \\
\text { size }\end{array}$} & \multicolumn{3}{|c|}{ Prevalence of malocclusion } \\
\hline & & & & & & & overall & Boys & Girls \\
\hline 1 & $\begin{array}{l}\text { Bhagyalaxmi A } \\
\text { [49] }\end{array}$ & IOTN & 10 & 2017 & Karnataka & 409 & 58.2 & 60.1 & - \\
\hline 2 & Chaitra K [50] & IOTN & 10 & 2014 & Karnataka & 1,000 & 75.9 & 47.9 & 44.8 \\
\hline 3 & Singh J [51] & IOTN & 10 & 2011 & Karnataka & 529 & 47.4 & 50.6 & 43 \\
\hline 4 & Kumar P [52] & IOTN & 8 & 2013 & Maharashtra & 1,200 & 53.7 & 34.2 & 34.3 \\
\hline 5 & Shashidhar J [53] & IOTN & 12 & 2018 & Karnataka & 500 & 35.5 & - & - \\
\hline 6 & Singh S [54] & IOTN & 10 & 2014 & Himachal & 2,000 & 68.4 & - & - \\
\hline 7 & $\begin{array}{l}\text { Bhagyalaxmi A } \\
\text { [55] }\end{array}$ & IOTN & 12 & 2015 & Karnataka & 363 & 80.4 & - & - \\
\hline 8 & Sachdeva A [56] & IOTN & 12 & 2016 & MP & 1,822 & 85.5 & - & - \\
\hline 9 & Vishnoi P [57] & IOTN & 8 & 2017 & Rajasthan & 1,029 & 51.2 & - & - \\
\hline 10 & Bhatia R [58] & IOTN & 10 & 2016 & Maharashtra & 604 & 41.3 & 43.6 & 39.2 \\
\hline 11 & Kaur H [59] & Angles & 10 & 2013 & Karnataka & 2,400 & 87.6 & - & - \\
\hline 12 & Patil D [60] & Angles & 12 & 2017 & Karnataka & 800 & - & 71 & 69.9 \\
\hline 13 & Kumar M [61] & Angles & 8 & 2014 & Maharashtra & 985 & 33 & 43 & 42 \\
\hline 14 & Trehan M [62] & Angles & 9 & 2009 & Rajasthan & 700 & 66.7 & 67.2 & 64.5 \\
\hline 15 & $\begin{array}{c}\text { Prabhakar RR } \\
\text { [63] }\end{array}$ & Angles & 8 & 2014 & Tamilnadu & 532 & 89.2 & 45.8 & 43.3 \\
\hline 16 & Reddy ER [64] & Angles & 12 & 2013 & $\begin{array}{l}\text { Andhra } \\
\text { Pradesh }\end{array}$ & 2,135 & 51.7 & - & - \\
\hline 17 & Retna KN [65] & Angles & 11 & 2016 & Kerala & 2,366 & 83.3 & 85.5 & 80.7 \\
\hline 18 & Das UM [66] & Angles & 8 & 2008 & Karnataka & 745 & 70.6 & 73.4 & 67.7 \\
\hline & & & & & & & $\begin{array}{r}\text { Mesial } \\
\text { step }\end{array}$ & $\begin{array}{r}\text { Distal } \\
\text { step }\end{array}$ & $\begin{array}{r}\text { Flush } \\
\text { terminal }\end{array}$ \\
\hline 19 & Khan R [67] & Terminal plane & 9 & 2014 & Uttar Pradesh & 453 & 31.3 & 6.4 & 62.3 \\
\hline 20 & Hedge S [68] & Terminal plane & 9 & 2012 & Rajasthan & 200 & 50 & 1 & 49 \\
\hline 21 & Bhayya D $[69,70]$ & Terminal plane & 11 & 2012 & Karnataka & 1,000 & 36.9 & 8.4 & 52.5 \\
\hline 22 & Bahadure RN [71] & Terminal plane & 8 & 2012 & Maharashtra & 1053 & 57.3 & 11.7 & 31.1 \\
\hline 23 & Fernandes S [72] & Terminal plane & 10 & 2017 & Gujarat & 383 & 43.3 & 1.3 & 55.4 \\
\hline 24 & Anitha XL [73] & Terminal plane & 10 & 2013 & Tamilnadu & 1,836 & 38 & 21 & 41 \\
\hline 25 & Lochit S [74] & Terminal plane & 8 & 2014 & Haryana & 1,000 & 12.8 & 2.4 & 65.1 \\
\hline
\end{tabular}

prevalence range of $0-26.7 \%$, whereas, our review shows a pooled prevalence of $2.2 \%$ only. Studies have reported a low prevalence of class III malocclusion in Indian children when compared with other racial groups $[8,80]$.

The evaluation of terminal plane relationship of primary second molars can act as predictor for assessing future malocclusions in children. Pooled estimates of our review shows that half of Indian children have flush terminal plane or commonly known as end-on relationship. The future forward growth of mandible can lead to development of class III malocclusion in children with flush terminal relationship [81]. We observed a higher prevalence of malocclusion among Indian boys as compared to girls. These results are contradictory to the trends seen in Iran [7] where girls had a higher prevalence of malocclusion. No gender difference was observed among the Chinese children [8].

\section{Strengths and limitations}

One of the limitations of the present review is that we didn't search data from grey literature which might be relevant to this review. Other major limitation is the occurrence of statistically significant heterogeneity among primary studies. We were unable to identify the source/s of this heterogeneity although we have used random effect model for estimation of results. The variation in quality of studies could be another possible limitation. In spite of these limitations, our review has many positive aspects. It is the first systematic review where all the studies conducted using most common indices and classification used for recording malocclusion were included for pooled analysis. We have followed international guidelines for data search and extraction and each study was scrutinized for its quality based on criteria 
Table 3: Cumulative prevalence estimate of malocclusion among Indian children according to different indices and classification.

\begin{tabular}{|c|c|c|c|c|c|c|c|}
\hline \multirow[t]{2}{*}{ Index/classification } & \multirow{2}{*}{$\begin{array}{l}\text { Categories of } \\
\text { malocclusion }\end{array}$} & \multirow{2}{*}{$\begin{array}{r}\text { Sample } \\
\text { size }\end{array}$} & \multirow{2}{*}{$\begin{array}{r}\text { Overall Pooled } \\
\text { prevalence } \\
(95 \% \mathrm{Cl})\end{array}$} & \multicolumn{2}{|r|}{ boys } & \multicolumn{2}{|r|}{ Girls } \\
\hline & & & & $\begin{array}{r}\text { Sample } \\
\text { size }\end{array}$ & $\begin{array}{r}\text { Pooled prevalence } \\
(95 \% \mathrm{Cl})\end{array}$ & $\begin{array}{r}\text { Sample } \\
\text { size }\end{array}$ & $\begin{array}{r}\text { Pooled prevalence } \\
(95 \% \mathrm{Cl})\end{array}$ \\
\hline \multirow[t]{5}{*}{ Dental aesthetic index } & No malocclusion & 71,409 & $\begin{array}{r}71.2(67.6 \\
74.6)\end{array}$ & 14,024 & $63.6(56.9,70.06)$ & 12,176 & $66.3(60.9,71.4)$ \\
\hline & Definitive & & $\begin{array}{r}15.4(13.5 \\
17.3)\end{array}$ & & $20.3(16.9,24.02)$ & & $19.2(16.6,21.8)$ \\
\hline & Severe & & $6.2(5.2,7.3)$ & & $8.4(6.5,10.4)$ & & $7.1(5.8,8.6)$ \\
\hline & Very severe & & $4.8(3.7,6.1)$ & & $3.8(2.7,5)$ & & $3.5(2.4,4.7)$ \\
\hline & Overall prevalence & & $\begin{array}{r}28.4(25.02 \\
31.9)\end{array}$ & & $43.6(35.5,51.9)$ & & $28.1(23.1,33.3)$ \\
\hline \multirow[t]{4}{*}{$\begin{array}{l}\text { Index of orthodontic } \\
\text { treatment needs }\end{array}$} & Little/no need & 9,456 & $\begin{array}{r}41.1(28.6, \\
54.2)\end{array}$ & 2,209 & $52.8(43.5,62.04)$ & 1,533 & $59.7(54.7,64.7)$ \\
\hline & Moderate & & $\begin{array}{r}25.3(20.2, \\
30.7)\end{array}$ & & $17.7(7.6,31.02)$ & & $14.3(4.5,28.3)$ \\
\hline & Definitive & & $\begin{array}{r}36.01(20.6 \\
53)\end{array}$ & & $16.5(5.2,32.4)$ & & $24.1(13.1,37.1)$ \\
\hline & Overall prevalence & & $\begin{array}{r}60.4(49.2 \\
71.1)\end{array}$ & & $47.17(37.9,56.4)$ & & $40.2(35.2,45.2)$ \\
\hline \multirow[t]{5}{*}{ Angles classification } & No malocclusion & 10,663 & $\begin{array}{r}31.9 \\
(18.7,46.7)\end{array}$ & 3,374 & $34.8(20.8,50.4)$ & 2,559 & $38.09(24.6,52.5)$ \\
\hline & Class 1 & & $\begin{array}{r}51.3(36.2, \\
66.3)\end{array}$ & & $44.1(25.9,63.2)$ & & $40.5(21.4,61.2)$ \\
\hline & Class 2 & & $10.2(6.3,14.9)$ & & $7.97(5.1,11.3)$ & & $8.26(5.1,12.07)$ \\
\hline & Class3 & & $2.2(0.8,4.2)$ & & $1.53(0.47,3.18)$ & & $0.93(0.1,2.5)$ \\
\hline & Overall prevalence & & $\begin{array}{r}66.7(50.7, \\
81.06)\end{array}$ & & $66.8(52.3,79.9)$ & & $60.4(52.3,68.1)$ \\
\hline \multirow{4}{*}{$\begin{array}{l}\text { Terminal plane } \\
\text { relationship }\end{array}$} & Mesial step & 5,925 & $37.7(26,50.2)$ & & - & & - \\
\hline & Distal step & & $6(2.3,11)$ & & - & & - \\
\hline & Flush terminal & & $\begin{array}{r}50.6 \\
(40.6,60.6)\end{array}$ & & - & & - \\
\hline & $\begin{array}{l}\text { Asymmetric } \\
\text { relationship }\end{array}$ & & $1.8(0,5.7)$ & & - & & - \\
\hline
\end{tabular}

covering different aspects of reporting a descriptive survey. We searched different electronic databases for this review thereby leading to higher number of included studies and larger sample size. All these points improve the generalizability of our results.

\section{Conclusions}

Apart from these functional problems, malocclusion has a significant impact on the social esteem and emotional well-being of a person. All the visible malocclusions have often been associated with bullying and a lower selfesteem among teenagers [76, 82]. A recent systematic review reported that malocclusion has a negative impact on oral health related quality of life of individuals [83]. Therefore, the knowledge of burden of malocclusion in a population is important for instituting preventive measures especially in children and adolescents to avoid its physical and psychosocial impact later in their life.

To conclude, the pooled data analysis of this review showed that the prevalence of malocclusion is increasing in Indian children. The reason for higher prevalence of malocclusion among Indian boys in comparison to girls needs to be investigated further. These results can help policy makers to work on feasible preventive and interceptive orthodontic measures for controlling malocclusion among Indian children and adolescents.

Research funding: None declared.

Author contributions: All authors have accepted responsibility for the entire content of this manuscript and approved its submission.

Competing interests: Authors state no conflict of interest. 


\section{References}

1. Graber T. Orthodontics: principles and practice, 3rd ed. Philadelphia: Saunders; 1972.

2. Paulsson L, Söderfeldt B, Bondemark L. Malocclusion traits and orthodontic treatment needs in prematurely born children. Angle Orthod 2008;78:786-92.

3. Cons NC, Jenny J, Kohout FJ, DDS YS, Jotikastira D. Utility of the dental aesthetic index in industrialized and developing countries. J Public Health Dent 1989;49:163-6.

4. Brook PH, Shaw WC. The development of an index of orthodontic treatment priority. Eur J Orthod 1989;11:309-20.

5. Angle EH. Classification of malocclusion. Dent Cosm 1988;41: 248-64.

6. Bishara SE, Hoppens BJ, Jakobsen JR, Kohout FJ. Changes in the molar relationship between the deciduous and permanent dentitions: a longitudinal study. Am J Orthod Dentofac Orthop 1988;93:19-28.

7. Akbari M, Lankarani KB, Honarvar B, Tabrizi R, Mirhadi H, Moosazadeh M. Prevalence of malocclusion among Iranian children: a systematic review and meta-analysis. Dent Res J (Isfahan) 2016;13:387-95.

8. Shen L, He F, Zhang C, Jiang H, Wang J. Prevalence of malocclusion in primary dentition in mainland China, 1988-2017: a systematic review and meta-Analysis. Sci Rep 2018;8:2-11.

9. Petersen PE. The World oral health report 2003 WHO global oral health programme. Community Dent Oral Epidemiol 2003;31: 3-23.

10. Bali RK, Mathur VB, Talwar PP, Channa HB. National oral health survey \& fluoride mapping. New Delhi: Dental Council of India; 2002.

11. Census of India; 2011. Available from: https://www.censusindia. gov.in/vital_statistics/srs_report/9chap 2 - 2011.pdf [Accessed 23 July 2018].

12. Janakiram C, Sanjeevan V, BR R, Joseph J, Stauf N, Benzian H. Political priority of oral health in India: analysis of the reasons for neglect. J Public Health Dent 2017;78:144-53.

13. Moher D, Liberati A, Tetzlaff J, Altman DG. Preferred reporting items for systematic reviews and meta-analyses: the PRISMA statement. PLoS Med 2009;6:e1000097.

14. Moosazadeh M, Nekoei-moghadam M, Emrani Z, Amiresmaili M. Prevalence of unwanted pregnancy in Iran: a systematic review and meta-analysis. Int J Health Plann Manage 2014;29:277-90.

15. Baskaradoss J, Geevarghese A, Roger C, Thaliath A. Prevalence of malocclusion and its relationship with caries among school children aged 11 - 15 years in southern India. Korean J Orthod 2013;43:35-41.

16. Bhardwaj VK, Veeresha KL, Sharma KR. Prevalence of malocclusion and orthodontic treatment needs among 16 and 17 year-old school-going children in Shimla city, Himachal Pradesh. Indian J Dent Res 2011;22:16-20.

17. Rudraiah B, Shekar C, Suma S, Kumar S, Sukhabogi JR. Malocclusion status among 15 years old adolescents in relation to fluoride concentration and area of residence. Indian J Dent Res 2013;24:1-8.

18. Damle D, Dua V, Mangla R, Khanna M. A study of occurrence of malocclusion in 12 and 15 year age group of children in rural and backward areas of Haryana, India. J Ind Soc Pedo Preven Dent 2014;32:12-17.
19. Jha K, Saha S, Jagnatha G, Narang R, Biswas G. Prevalence of malocclusion and its psycho-social impact among 12 to 15 -Yearold school children in Lucknow city. J Clin Diagn Res 2014;8: 36-9.

20. Nagalakshmi S, James S, Rahila C, Balachandar K, Satish R. Assessment of malocclusion severity and orthodontic treatment needs in 12 - 15 - year - old school children of Namakkal district, Tamil Nadu, using Dental Aesthetic Index. J Ind Soc Pedo Preven Dent 2017;35:188-92.

21. Shetty R, Hegde V, Shetty P. Assessment of malocclusion status, dentition status, and treatment needs among 15 - year - old school children of Mangalore. Indian J Dent Res 2018;29:109-16.

22. Sanadhya S, Chadha M, Chaturvedi MK, Chaudhary M. Prevalence of malocclusion and orthodontic treatment needs among 12 - 15-year-old schoolchildren of fishermen of Kutch Coast, Gujarat, India. Int Marit Heal 2014;65:106-13.

23. Shivakumar K, Chandu G, Subba Reddy V, Shafiulla M. Prevalence of malocclusion and orthodontic treatment needs among middle and high school children of Davangere city, India by using Dental Aesthetic Index. J Ind Soc Pedo Preven Dent 2009; 27:211-18.

24. Nagarajan S, Pushpanjali K. The relationship of malocclusion as assessed by the Dental Aesthetic Index (DAl) with perceptions of aesthetics, function, speech and treatment needs among 14- to 15-year-old schoolchildren of Bangalore, India. Oral Health Prev Dent 2010;8:221-8.

25. Fotedar S, Sogi G, Kapil R, Pruthi N. Oral health status and treatment needs among 12- and 15-year-old government and private school children in Shimla city, Himachal Pradesh, India. J Int Soc Prev Community Dent 2013;3:44-50.

26. Tak M, Nagarajappa R, Sharda AJ, Asawa K, Tak A. Prevalence of malocclusion and orthodontic treatment needs among $12-15$ years old school children of Udaipur, India. Eur J Dent 2013;7: 45-53.

27. SureshBabu, Chandu G, Shafiulla M. Prevalence of malocclusion and orthodontic treatment needs among 13-15 Year old school going children of Davangere city, Karnataka. J Indian Assoc Public Heal Dent 2020;5:32.

28. Chandra Shekar B, Suma S, Kumar Sukhabogi J, Manjunath B. Prevalence of malocclusion among 15-year-old school children using dental aesthetic index in Nalgonda district, Andhra Pradesh, India: a cross-sectional study. J Indian Assoc Public Heal Dent 2014;12:173-8.

29. Reddy V, Hemapriya S, Chaly P, Ingle N. Prevalence of malocclusion and orthodontic treatment needs among 12 - 15 years old school children of Udaipur, India. J Indian Assoc Public Heal dent 2011;2011(18 suppl-1):591-8.

30. Athuluru D, Reddy VC, Sudhir KM, Kumar R V, Krishna S, Gomasani S. An epidemiological data of oral health status and treatment needs of rural population of Nellore district, Andhra Pradesh, India. J Ind Assoc Public Heal Dent 2016;14:281-6.

31. Hemapriya S, Ingle N, Chaly P, Reddy V. Prevalence of Malocclusion and orthodontic treatment needs among 12 to 15 year old rural school children in Kancheepuram district of Tamilnadu. J Oral Heal Community Dent 2013;7:84-90.

32. Kaipa S, Margabandhu S, Fareed N. Malocclusion and orthodontic treatment needs among adolescents in Nellore district of Andhra Pradesh, India. J Ind Assoc Public Heal Dent 2013;11:36-43. 
33. Khan MK, Sharma A, Thakar SS, Jain M, Seth N, Pandey A. Prevalence of malocclusion and treatment needs among secondary school children in Gautam Buddh Nagar, Uttar Pradesh. J Med Erud 2017;5:01-14.

34. Pruthi N, Sogi P, Fotedar S. Malocclusion and deleterious oral habits in a north Indian adolescent population: a correlational study. Eur J Gen Dent 2013;2:257.

35. Reddy S, John J, Sarvanan S, Arumugham I. Normative and perceived orthodontic needs among 12 year old school children in Chennai, India. Appl Technol Innov 2010;3:40-7.

36. Gupta R, ChandraShekar BR, Goel P, Saxena V, Ganavadiya R, Verma N. Prevalence of malocclusion in relation to area of residence among 13-15 years old government and private school children in Bhopal district, Madhya Pradesh, India. Int J Adv Res 2015;3:918-25.

37. Sushanth V, Krishna M, SureshBabu A, Prashant G, Madankumar $P$, Shivakumar M. Prevalence of malocclusion and orthodontic treatment needs among 12 - 13 Year old school going children in Chennai City, Tamilnadu, India. Int J Oral Heal Med Res 2015;2: 32-8.

38. Thakur AS, Acharya S, Singhal D, Rewal N, Bhardwaj VK. Oral health status and oral health behaviors of 12 - year - old Urban and rural school children in Udupi, Karnataka, India 6:12-16.

39. Suma S, Chandrashekar B, Manjunath B. Assessment of malocclusion status in relation to area of residence among 15 year old school children using Dental Aesthetic Index. Int J Dent Clin 2011;3:14-17.

40. Shivakumar K, Chandu G, Shafiulla M. Severity of malocclusion and orthodontic treatment needs among 12- to 15-year-old school children of Davangere district, Karnataka, India. Eur J Dent 2010; 4:298-307.

41. Handa S, Prasad S, Rajashekharappa CB, Garg A, Ryana H, Khurana C. Oral health status of rural and Urban population of Gurgaon block, Gurgaon district using WHO assessment Form through Multistage sampling technique. J Clin Diag Res 2016;10: 43-51.

42. John J, Dhinahar S, Reddy P. Prevalence of malocclusion and treatment needs of 12 year old school children, Chennai using the dental aesthetic index (DAI). J Pierre Fauchard Acad 2011;25: 14-44.

43. Sivakumar V, Jain J, Haridas R, Paliayal S. Oral health status of Tibetan and local school Children 10:29-33.

44. Prasad SN, Srinivasan I, Setty JV. Prevalence and impact of malocclusion on parents and children aged 10-12 years - a prospective study. J Dent Med Sci 2016;15:38-45.

45. Mallick S, Imranulla M, kumar PG N, Prashant G, Sushanth VH, Rubel M. Assessment of malocclusion status in 15 year old school children of a south Indian city- A cross- sectional survey. Int J Biomed Res 2017;8:26-32.

46. Kumar N, Mohapatra A, Ramesh N, Ravishankar T. Prevalence of malocclusion and orthodontic treatment need among 12-15 Years old school children in. Pakistan Oral Dent J 2010;30:181-5.

47. Singh A, Purohit B, Sequeira P, Acharya S, Bhat M. Malocclusion and orthodontic treatment need measured by the dental aesthetic index and its association with dental caries in Indian schoolchildren. Community Dent Health 2011;28:313-6.

48. Gaikwad SS, Gheware A, Kamatagi L, Pasumarthy S, Pawar V, Fatangare M. Dental caries and its relationship to malocclusion in permanent dentition among 12-15 year old school going children. J Int oral Heal 2014;6:27-30.
49. Bhagyalakshmi A, Shivalinga B, Nitin V, Avinash B, Suma S. IOTN index based malocclusion assessment of 12 year old school going children in Mysore city. Int J Adv Res 2015;3:1235-40.

50. Chaitra K, Reddy N, Reddy S, Vanishree. Orthodontic treatment: need and demand in north Karnataka school children. J Clin Diag Res 2014;8:37-42.

51. Singh J, Kaur I, Sequeira PS. Prevalence of various types of malocclusion and treatment needs among high school children aged between 12-15 years in Udupi Taluk, south Karnataka - an epidemiological study. J Ind Assoc Public Heal Dent 2011;18.

52. Kumar P, Londhe S, Kotwal A, Mitra R. Prevalence of malocclusion and orthodontic treatment need in schoolchildren e an epidemiological study. Med J Armed Forces India 2012;9: 2-7.

53. Shashidhar J, chandrashekher S. Orthodontic treatment need in higher primary schoolchildren of central Bengaluru, India. J Int Soc Prev Community Dent 2018;8:235-9.

54. Singh S, Sharma A, Sandhu N, Mehta K. The prevalence of malocclusion and orthodontic treatment needs in school going children of Nalagarh, Himachal Pradesh. Indian J Dent Res 2016; 27:317-22.

55. Avinash B, Shivalinga BM, Balasubramanian S, Ravikumar M, Shekar S, Chandrashekar BR, et al. Geographic information system and index of orthodontic treatment need: tools to assess orthodontic treatment needs of 12-year-old children of Mysuru district. J Indian Assoc Public Heal Dent 2017;15:348-53.

56. Sachdeva A, Raghav S, Baheti K, Ali M, Goel M. Assessment of orthodontic treatment needs among school going children using index of orthodontic treatment need (IOTN) in indore (Central India), Madhya Pradesh, India. EC Dent Sci 2016;4:908-18.

57. Vishnoi P, Shyagali TR, Bhayya DP. Prevalence of need of orthodontic treatment in 7-16-year-old school children in Udaipur city, India. Turkish J Orthod 2017;30:73-7.

58. Bhatia R, Winnier J, Mehta N. Impact of malocclusion on oral health-related quality of life in 10-14-year-old children of Mumbai, India. Contemp Clin Dent 2016;7:445.

59. Kaur H, Pavithra U, Abraham R. Prevalence of malocclusion among adolescents in South Indian population. J Int Soc Prev Community Dent 2013;3:97.

60. Disha P, Poornima P, Pai S, Nagaveni N, Roshan N, Manoharan M Malocclusion and dental caries experience among 8-9-year-old children in a city of South Indian region: a cross-sectional survey. J Educ Health Promot 2017;6:98.

61. Kumar M, Banerjee P, Gondhalekar R, Gondhalekar R, Lall R. Dental occlusion among school going children of Maharashtra. J Int Oral Heal 2014;6:53-5.

62. Trehan M, Chugh V, Sharma S. Prevalence of malocclusion in Jaipur, India. Int J Clin Pediatr Dent 2009;2:23-5.

63. Prabhakar R, Saravanan MK, Karthikeyan C, Sudeepthi V. Prevalence of malocclusion and need for Early orthodontic treatment in children. J Clin Diagn Res 2014;8:60-1.

64. Reddy E, Manjula M, Sreelakshmi N, Rani S, Aduri R, Patil B. Prevalence of malocclusion among 6 to 10 Year old Nalgonda school children. J Int Oral Heal 2013;5:49-54.

65. Kumari R, Jasem M, Kumar T. Prevalence of malocclusion among $10-$ 12-year-old schoolchildren in Kozhikode district, Kerala 9:50-5.

66. Das UM, Reddy D. Original article prevalence of malocclusion among school children in Bangalore, India. Int J Clin Pediatr Dent 2008;1:10-12. 
67. Khan R, Singh N, Govil S, Tandon S. Occlusion and occlusal characteristics of primary dentition in North Indian children of East Lucknow region. Eur Arch Paediatr Dent 2014;15:293-9.

68. Hegde S, Panwar S, Bolar D, Sanghavi M. Characteristics of occlusion in primary dentition of preschool children of Udaipur. Eur J Dent 2012;6:51-5.

69. Bhayya DP, Shyagali TR, Dixit UB, Shivaprakash. Study of occlusal characteristics of primary dentition and the prevalence of maloclusion in 4 to 6 years old children in India. Dent Res J 2012;9:619.

70. Bhayya DP, Shyagali TR. Gender influence on occlusal characteristics of primary dentition in 4- to 6-year-old children of Bagalkot City, India. Oral Heal Prev Dent 2011;9:17-27.

71. Bahadure R, Thosar N, Gaikwad R. Occlusal traits of deciduous dentition of preschool children of Indian children. Contemp Clin Dent 2012;3:443.

72. Fernandes S, Patel DG, Ranadheer E, Kalgudi J, Santoki J, Chaudhary S. Occlusal traits of primary dentition among preschool children of Mehsana District, North Gujarat, India. J Clin Diagnostic Res 2017;11:ZC92-6.

73. Anitha XL, Asokan S. Occlusion characteristics of preschoolers in Chennai: a cross-sectional study. J Dent Child 2013;80:62-6.

74. Lochib S, Indushekar KR, Saraf BG, Sheoran N, Sardana D. Occlusal characteristics and prevalence of associated dental anomalies in the primary dentition. J Epidemiol Glob Health 2015; 5:151-7.
75. World Health Organization. Oral health surveys- basic methods. Geneva: World Health Organization; 1997.

76. Dimberg L, Arnrup K, Bondemark L. The impact of malocclusion on the quality of life among children and adolescents: a systematic review of quantitative studies. Eur J Orthod 2015;37: 238-47.

77. Zhang M, McGrath C, Hagg U. The impact of malocclusion and its treatment on quality of life: a literature review. Int J Paediatr Dent 2006;16:381-7.

78. English JD, Buschang PH, Throckmorton GS. Does malocclusion affect masticatory performance?. Angle Orthod 2002;72:21-7.

79. Bourzgui F, El Quars F. Prevalence of malocclusions and orthodontic treatment need in 8- to 12-year-old schoolchildren in Casablanca, Morocco. Prog Orthod 2012;13:164-72.

80. Hardy DK, Cubas YP, Orellana MF. Prevalence of angle class III malocclusion: a systematic review and meta-analysis. Open J Epidemiol 2012;02:75-82.

81. Baume LJ. Physiological tooth Migration and its significance for the development of occlusion. J Dent Res 1950;29:123-32.

82. Helm S, Petersen PE, Kreiborg S, Solow B. Effect of separate malocclusion traits on concern for dental appearance. Community Dent Oral Epidemiol 1986;14:217-20.

83. Kragt L, Dhamo B, Wolvius EB, Ongkosuwito EM. The impact of malocclusions on oral health-related quality of life in children-a systematic review and meta-analysis. Clin Oral Investig 2016;20: 1881-94. 